\title{
alphanumeric journal
}

The Journal of Operations Research, Statistics, Econometrics and Management Information Systems

Volume 6, Issue 2, 2018

Received: February 08, 2018 Accepted: December 28, 2018 Published Online: December 31, 2018

\author{
AJ ID: 2018.06.02.0R.05 \\ DOI: 10.17093/alphanumeric.392217 \\ Research Article
}

\section{A Process Innovation and Its Application in Production and Operations Management}

Banu Özkeser, Ph.D.

Koluman Otomotiv Endüstri A.Ş., Mersin, Turkey, banuozkeser@gmail.com

* Şahin Mh. Sait Polat Blv. No:386 (D 400 Karayolu üzeri, Yenice Otoyol Çıkışı), 33800 Tarsus, Mersin, Türkiye

\begin{abstract}
Assembly line, one of the most important study-fields of both manufacturing and operations management and operations research, has continued to be a popular field regarding to the technological improvements for the searchers. In the result of process innovation by balancing the stations in the assembly line; the engineering studies, done in the period which is from the first step of the production till the last step that the product is done, have significant results by means of analyzing the different parameters. One of these studies is done in the content of this article regarding to the product of the light truck line of a company in the automotive field. The main targets of this article are; determining the minimum station numbers for assembly line, the operations done in every station and the lost balance of the line. Finally, the results expected in the result of the developed algorithm is written below; Minimizing the late times of the orders, Balancing the used capacity, Minimizing the flow times, Minimizing the late work orders, Balancing the used capacities of the machines and the equipment,
\end{abstract}

Keywords: $\quad$ Production Management, Process Innovation, Line Balancing

\section{Üretim ve Operasyon Yönetiminde Bir Süreç İnovasyonu ve Uygulaması}

Gerek üretim ve operasyon yönetiminin gerekse yöneylem araştırmasının önemli çalışma alanlarından olan montaj hatları, günümüzdeki teknolojik gelişimlere bağlı olarak araştırmacılar için büyük bir ilgi alanı oluşturmaya devam etmiştir. Montaj hattındaki istasyonların dengelenmesi ile yapılan süreç inovasyonu sonucunda, üretimin ilk aşamasından nihai ürün elde edilene kadar geçen süredeki farklı parametreler incelenerek yapılan mühendislik çalışmaları önemli ölçüde yararlı sonuçlar vermektedir. Bu çalışmaların bir uygulaması da bu çalışma kapsamında, otomotiv sektöründe üretim yapan bir firmanın ürünü ile ilgili gerçekleştirilmektedir. Montaj hattı için gerekli minimum istasyon sayısını, her istasyonda yapılacak işlem(ler)i ve tüm istasyonları ile hattın denge kaybının tespit edilmesi ana hedefi oluşturmaktadır. Özetle, oluşturulan algoritma ile elde edilmesi beklenen sonuçlar; Taleplerin gecikme süreleri minimizasyonu, Kullanım kapasitesi dengelemesi, Akış zamanlarının azaltılması, Geciken iş sayısının minimizasyonu, Makine kullanım oranlarının ayarlanması, 


\section{Giriş}

Üretim, ana prensibi topluma değer yaratmak olan, toplum ihtiyaçlarının doğa tarafından tamamen karşılanamaması sonucu ile ortaya çıkan ve insan gücü ile gerçekleştirilen bir faaliyettir.

Bu faaliyeti gerçekleştiren üretim sistemleri ise;

- Üretim Yöntemlerine göre

- Ürün tipine göre

- Üretim iş seyrine göre ve

- Üretim miktarı veya akışına göre sınıflandırılmaktadır. (Kobu, 1987).

Üretim miktarı ya da akışına göre sınıflandırılması göz önüne alındığı takdirde ise üç ana üretim tipi söz konusudur. Bunlar; kesikli üretim, talebe yönelik üretim ve seri üretimdir. Seri üretimin bir alt kolu olan montaj hattı ise operatör(ler), iş istasyonu, proses içi iş, malzeme taşıma sistemi, üretim çizelgeleri, insan kaynakları yönetim politikası, bakım-onarım politikası gibi bir çok bileşenden oluşmaktadır. Başka bir deyişle; malzemelerin, akış boyunca insan kaynağı ya da altyapıdan (teçhizattan) yararlanılarak transferinin sağlanması, parça üzerindeki operasyonların aralarındaki öncelik ilişkileri ve çevrim süresi gibi darboğaz oluşturan kısıtların dikkate alınarak birleştirilmesi sonucu oluşturulan istasyonların hat boyunca sıralanması ile meydana gelen sisteme “montaj hattı “ denilmektedir (Ağpak, Gökçen, Saray, Özel, 2002).

Dengeleme olmayan üretim hatlarının bazı istasyonlarında, diğer istasyonlara oranla daha yoğun iş yükü olacağı için, verimlilik açısından azalma yaşanması ve bazı kayıpların meydana gelmesi de kaçınılmazdır. İşlemlerin istasyonlara atanmasının planlanması süre ve gruplama kısıtları gibi bazı kısıtları da gündeme getirmektedir. Bu kısıtların olması tamamen bir hat dengelemesinin oluşturulmasını güçleştirir.

Montaj hatlarının dengeleme tasarımında büyük bir önem taşıyan iş elemanlarının öncelik ilişkilerini de belirtmek gerekmektedir.

İş elemanlarının kendi aralarındaki öncelik ilişkilerini etkileyen faktörlerden başlıcaları şunlardır;

- Teknolojik spesifikasyonlar

- Üretim ve montaj yöntemleri

- Büyük hacimler nedeniyle bazı makinelerin sadece belirli iş istasyonlarında görevlendirilme zorunluluğu

- Fabrika yerleşim düzeni

- Çalışanların emniyetleri için bazı işlemlerin montaj bandı dışında yapılması veya bazı özel giysilere veya yardımcı aletlere ihtiyaç duyulması (Toraman ve Gözlü, 1984).

Montaj hatlarıyla ilgili her gün gelişen bir literatür bulunmaktadır. Bowman, montaj hattı değişkenlerini iş elemanı üzerinde harcanan işlem süreleri olarak belirlerken, Hoffman öncelik İlişkisi matrisi kurmuştur. Mansoor ise istasyon sayısı ve çıtı verimlilik kapasitesini incelenmiştir. Diğer taraftan Thomopoulos, istasyon sayısını 
minimize etmeyi amaçlayan bir çalışma yapmıştır. Macaskill ise istasyonlara iş gruplarının atanmasıyla hat dengeleme yoluna giden bir inceleme gerçekleştirmiştir. Bu çalışmaların örneklerini arttırmak mümkündür.

\section{Materyal ve Metod}

\subsection{Materyal}

Materyal olarak otomotiv sektöründe yer alan büyük ölçekli ve yerli üretim yapan bir firmanın hafif kamyon montaj hattı incelenmiştir. Analiz edilen hat bozulduğunda hattın beklemelere neden olabilecek yatırım maliyeti yüksek, darboğaz oluşturan istasyonlara sahip tek modelli ve uygun adımlı bir hattır. Illk aşamada mevcut sistem detaylı olarak incelenmiş ve sonrasında belirlenen bazı performans kriterleriyle çalışma analiz edilmiştir. Materyal kısmını oluşturan bu performans ölçütleri şu şekilde sıralanmaktadır;

- Taleplerin Geliş Hızı \& Ortalama Akış Süresi

- Taleplerin Geliş Hızı \& Maksimum Akış Süresi

- Taleplerin Geliş Hızı \& Geciken Parça (Malzeme) Adedi

- Taleplerin Geliş Hızı \& Erken Biten Parça (Malzeme) Adedi

- Talep Geliş Hızı - Toplam Geç Kalma Süresi

- Talep Geliş Hızı-Toplam Erken Bitme Süresi

- Termin Süresi-Ortalama Akış Süresi

- Termin Süresi-Geç Kalan Parça Adedi

Uygulama etüdünün gerçekleştiği montaj hattı; iş akış rotası belli olan, k iş istasyonu bulunan ve $n$ adet işin geldiği, $d_{i}$ termin zamanına sahip olan bir üretim hattıdır. Hattın özellikleri ile göz önüne alınacak varsayımlar ise aşağıda özetlenmektedir;

- İstasyonlarda, makine, teçhizatlarda arıza söz konusu değildir, belirlenen kapasite doğrultusunda çalışılmaktadır.

- Talepler bir tek parti halinde üretilmektedir. Talep bölünmesi yapılmamaktadır.

- Kaynak yetersizliği gibi nedenlerden dolayı fazla mesai yoktur.

- Aynı işi yapan istasyonların kapasiteleri de aynıdır.

- iş̧ istasyonları arasında taşıma süreleri dikkate alınmamıştır.

- İstasyona gelen talebin reddi mümkün değildir.

- Kalitesizlik gibi durumlar dolayısıyla, taleplerin yeniden ele alınması söz konusu olamaz.

- Hazırık zamanı kuyrukta bekleme zamanının bir parçası olarak ele alınır, ayrı olarak düşünülemez. 
Çalışmada, SIMAN simülasyon dili araç olarak kullanılmıştır. Diğer özel amaçı simülasyon dilleri gibi SIMAN da belli alanlarda uzmanlaşmış ve özgün komut setleri kapsamaktadır.

\subsection{Metod}

Süreç inovasyonunu gerçekleştirmek üzere tasarlanan algoritmada ise istasyonların ortalama iş yükleri ortalama kuyrukta bekleme süreleri taleplerin geriye kalan aylak zamanları gibi birtakım bilgiler gerekmektedir. Problem formülasyonu için kullanılan notasyon aşağıdaki şekildedir;

$$
\begin{aligned}
& \text { i } \quad \text { :talep numarası i }=1,2,3, \ldots \ldots . n \\
& \text { k : :istasyon numarası } k=1,2,3, \ldots . .5 \\
& \mathrm{~d}_{\mathrm{i}} \quad: \text { i talebinin termin tarihi } \\
& \text { z : : Üretime başlanan tarih } \\
& q_{i} \quad: \text { i talebinin miktarı (adet) } \\
& \mathrm{S}_{\mathrm{i}} \quad \text { :i talebinin aylak zamanı (dakika) } \\
& \mathrm{W}_{\mathrm{k}(\mathrm{ort})}: \mathrm{k} \text { istasyonunun ortalama kuyrukta bekleme süresi (dakika) } \\
& P_{k} \quad: k \text { istasyonunun kuyruk uzunluğu (adet) } \\
& P_{k(o r t)} \quad: k \text { istasyonunun ortalama kuyruk uzunluğu (adet) } \\
& \mathrm{P}_{\mathrm{i}} \quad \text { : } \quad \text { talebinin } \mathrm{k} \text { istasyonundan sonra uğrayacağı bir sonraki istasyondaki } \\
& \text { kuyruk uzunluğu } \\
& t_{i k} \quad \text { :i talebinin k istasyonundaki birim işlem süresi (adet/dakika) } \\
& \mathrm{t}_{\mathrm{i}} \quad \text { : i talebinin } \mathrm{k} \text { istasyonundan sonra uğrayacağı istasyondaki birim işlem } \\
& \text { süresi (adet/dakika) } \\
& \mathrm{K}_{\mathrm{k}} \quad \mathrm{k} \text { istasyonunda bekleyen gecikmeli parçaların sayısı } \\
& M_{k} \quad: k \text { istasyonunda yapılmakta olan işlerin bitirme zamanlarının kümesi } \\
& \mathrm{Y}_{\mathrm{km}} \quad \text { :Atama yapılacak olan } \mathrm{k} \text { istasyonundaki m makinesi } \\
& \mathrm{L}_{\mathrm{i}} \quad \text { : i talebinin uğrayacağı son istasyon }
\end{aligned}
$$

Esas hedefi gecikme süresinin en aza indirgenmesi olarak saptanan bu algoritmanın önceliklerini şöyle açıklamak mümkündür;

1. Öncelik: Kuyrukta bekleyen montajı yapılacak parçaların en aza indirgenmesi

İş istasyonundaki bir operasyon bittiğinde ve yerine hangi parça geleceğine karar verirken işlem sırası bekleyen diğer montaj parçalarının önce boş zamanları hesaplanır. En küçük değere sahip olan talep de, işleme seçilir. Bu önceliğe göre;

$S_{i}=d_{i}-z-\left(t_{i}, q_{i}\right)$ hesaplaması yapılır, sonra; $S_{i}<0$ değilse üçüncü önceliğe geçilir. $S_{i}<0$ ise $\min \left(S_{i}\right) \in K_{k}$ değerine sahip malzemenin (parça) boş istasyona ataması tamamlanır. 


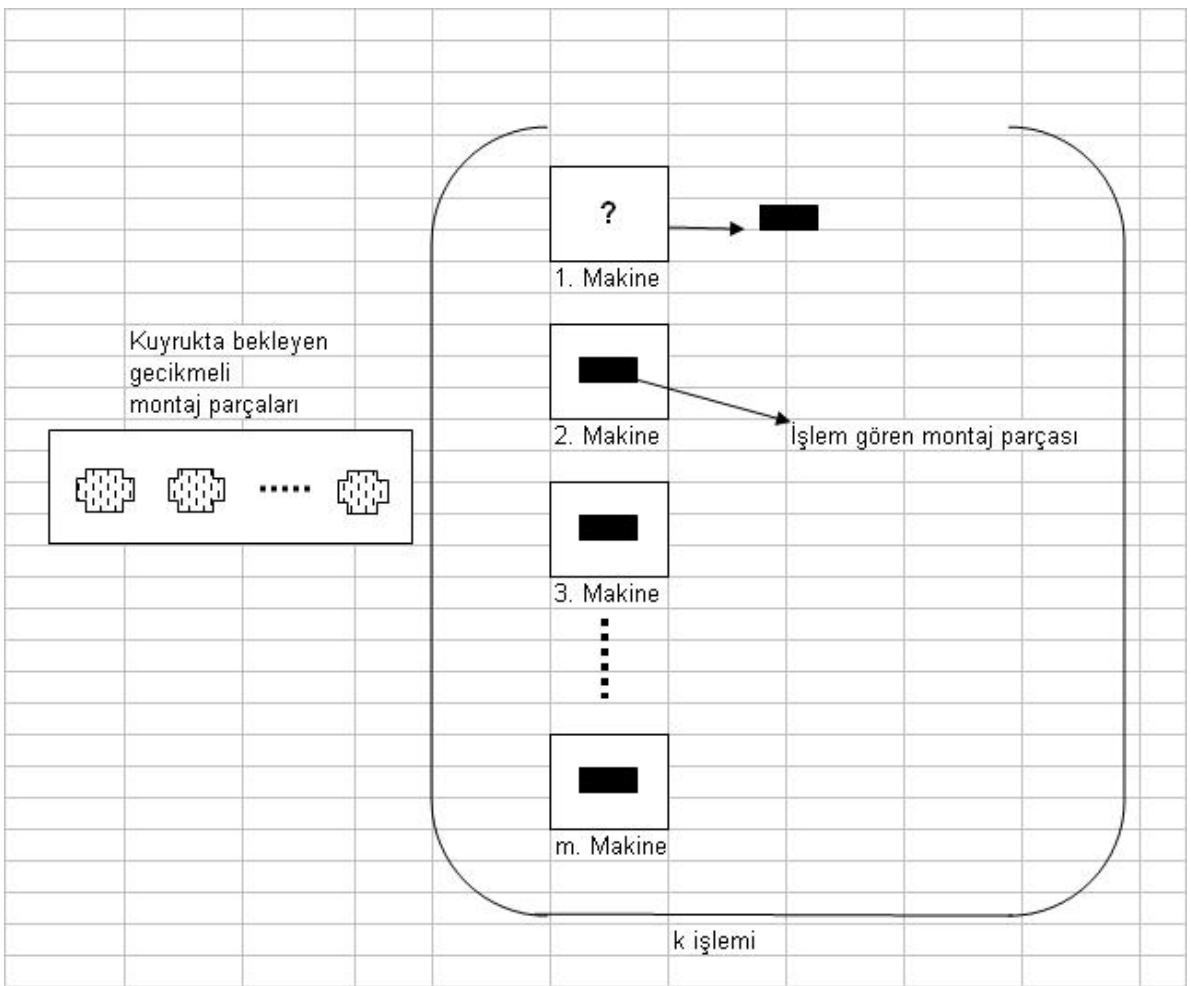

Şekil 1. Bekleyen montaj parçalarının minimizasyonu

\section{2. Öncelik: Kuyruktaki bekleyen montaj parçalarını dengeleme}

Gecikmesi muhtemel monte edilecek bir parça olmadığında, istasyonların iş yükünü dengelemeye yönelik, her bir iş istasyonunun kuyruktaki bekleyen parça sayıları hesaplanır. Eğer bu değer ortalama parça sayısından daha fazla ise; istasyon yoğundur. Yoğunluğu azaltmak için de kuyrukta bekleyen ve operasyon süresi en az olan montaj parçası işlem görmek üzere boş istasyona atanır. Bu önceliğe göre; $P_{k}>$ $P_{k(o r t)} \min \left(t_{i k}\right)$ değerine sahip olan malzeme (parça) boş istasyona atanır.

$P_{k}<P_{k(o r t)}$ 3. önceliğe geçilir.

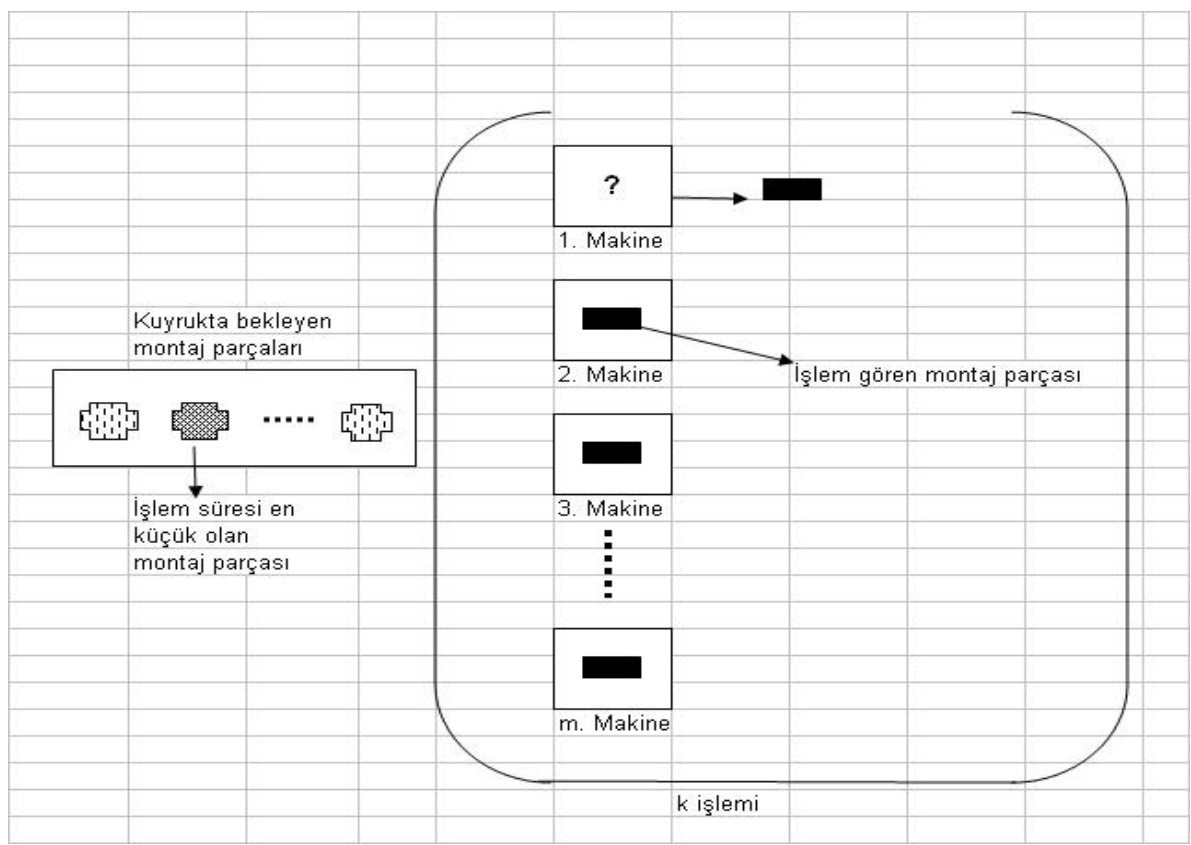

Şekil 2. Kuyruktaki bekleyen montaj parçalarını dengeleme 
3. Öncelik: Toplam iş yükünü dengeleme

Herhangi bir gecikmesi muhtemel bir montaj parçası olmadığı zaman ve istasyon önünde bekleyen parça sayısının ortalama sayının altında olduğu durumlarda daha sonraki istasyonların kuyrukta bekleyen parçalarını en aza indirgemek gerekir. Bu gerekçeyle, kuyruktaki parçaların bir sonraki istasyondaki operasyon süreleri hesaplanır ve en kısa zamana sahip olan, boş istasyona atanır. Bu önceliğe göre; $\min \left(t_{\mathrm{i}}\right)$ değerine sahip talep boş istasyona atanır.

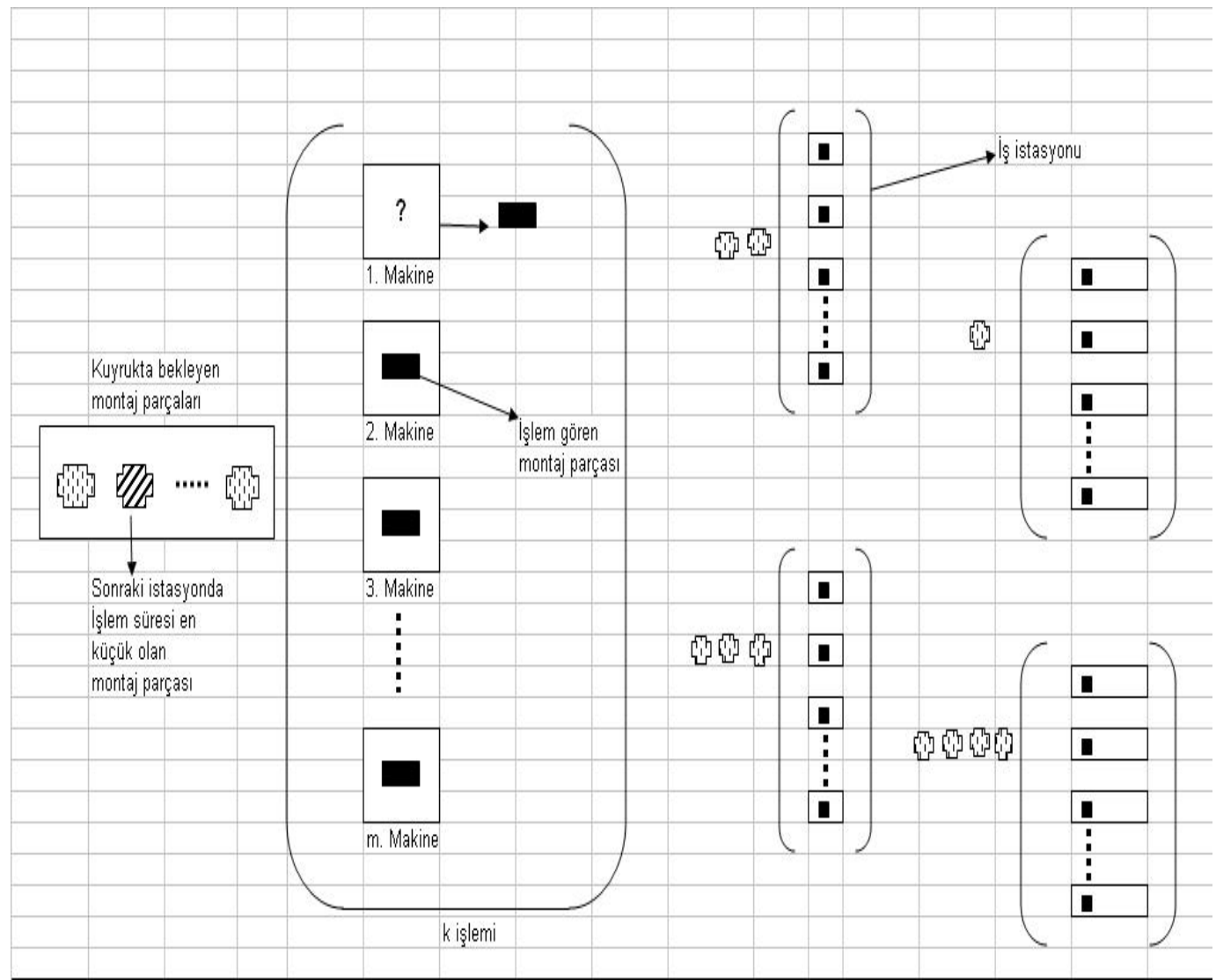

Şekil 3. Toplam iş yükünü dengeleme

\section{Bulgular ve Tartışma}

Talep bazlı çalışan işletmeler için süreç inovasyonunu sağlamak üzere tasarlanan algoritmanın performansının analiz edilmesi için karşılaştırma yapılacak iki adet sezgisel algoritma kullanılmıştır. Bunlar S/OP (Shortest Operation Time=En kısa işlem süresi) ve EDD (Earliest Due Date=En erken termin tarihli sıralama) kurallarıdır. Seçilen kurallardan birisi statik diğeri dinamik olup, yapılan literatür araştırmasında her iki kuralın da uygulamalarda sık olarak kullanıldığı ve performans ölçütlerinin değerlendirilmesinde oldukça iyi sonuçlar verdiği gözlemlenmiştir. Özellikle S/OP kuralının ortalama akış süresinin minimizasyonunda ve dolayısıyla da ara stok düzeyi ile gecikmelerde oldukça iyi sonuçlar vermesi beklenmektedir. EDD, temrin zamanına göre hareket eden bir kural olduğu için gecikmeleri minimize etmesi gerekmektedir.

\section{Taleplerin Geliş Hızı ile Ortalama Akıș Süresi.}

Sonuçlara göre, talep geliş hızları azaldıkça akış süreleri azalmakta, ancak bu azalma eğilimi EDD ile S/OP algoritmalarında birbirine benzer gerçekleşmektedir. Geliş̧ 
yoğunluğunun azalması eş zamanlı olarak mevcut sistem kaynaklarının kullanımındaki yoğunluğunun azalmasına neden olmaktadır. Sonuçlara bakılınca S/OP kuralı önceleri EDD'den daha kötü sonuçlar verdiği halde gelişler arası süre arttıkça EDD'ye göre daha iyi sonuçlar vermeye başladığı görülmektedir. Tasarlanan algoritma ise her iki yönteme göre yaklaşık olarak \%40 daha iyi sonuçlar vermektedir. Dolayısıyla süreçte somut olarak bir inovatif kazanım elde edilmiştir.

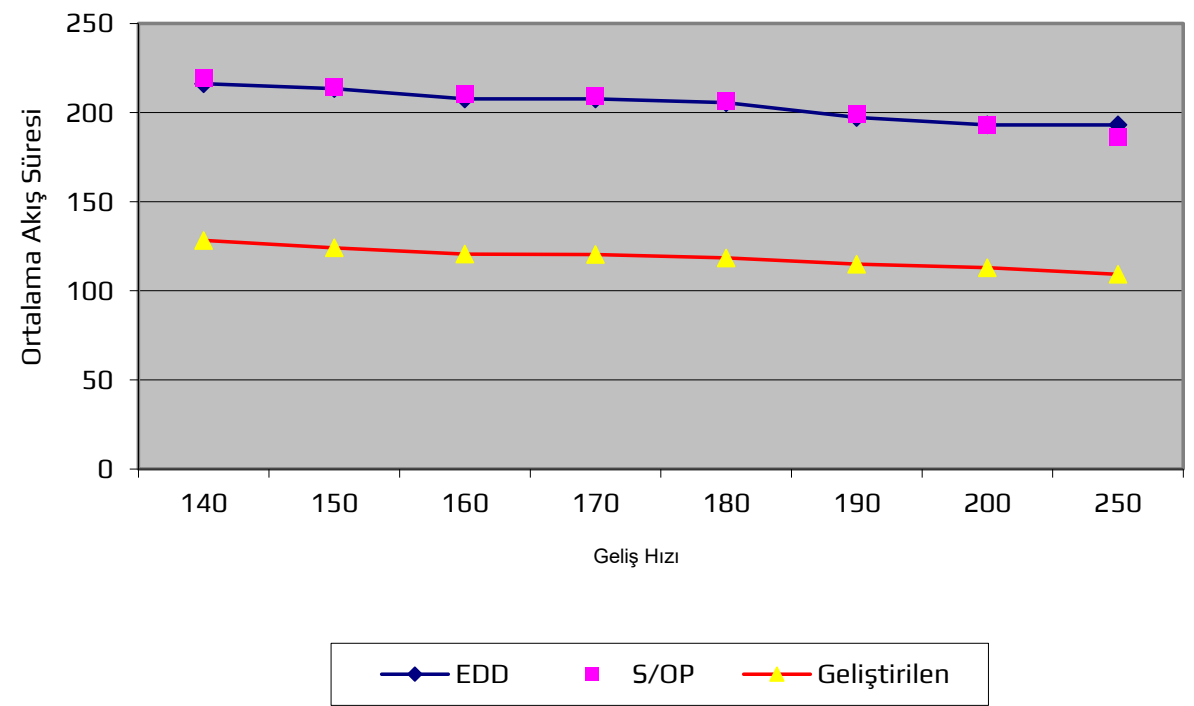

Şekil 4. Geliş Hızı-Ortalama Akış Süresi

\section{Taleplerin Geliş Hızı ile Maksimum Akış Süresi:}

Her kural için akış süresinin gerçekleşen en büyük değerini ele alarak, bütün olarak sistemin akış dengesinin tahmin edilmesi açısından değerlendirilebilen bir kriter olarak düşünülmesi mümkündür.

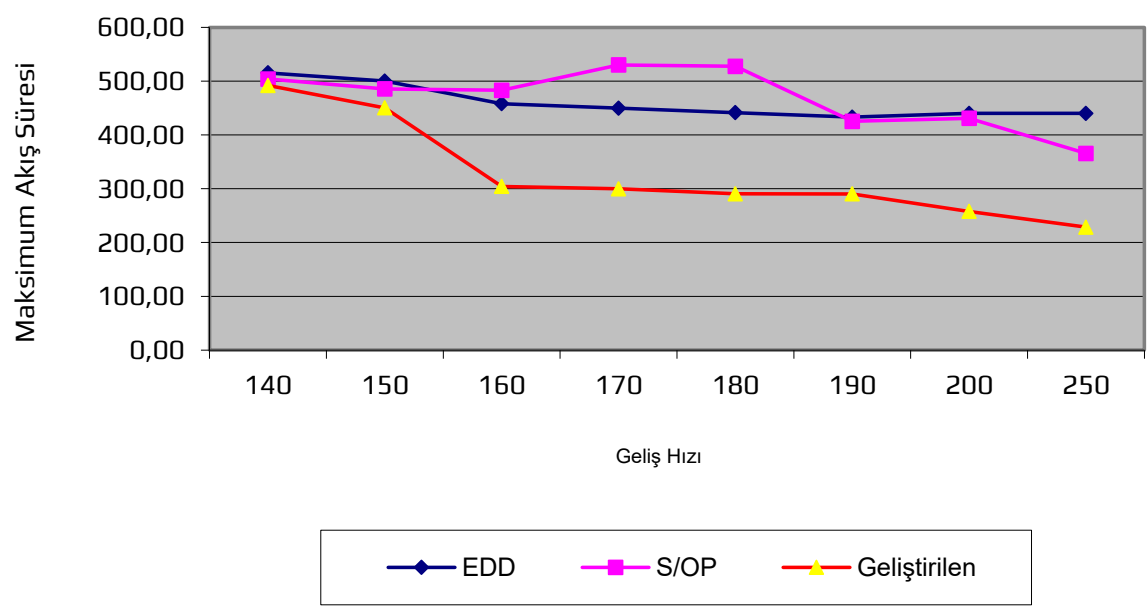

Şekil 5. Geliş Hızı-Maksimum Akış Süresi

\section{Taleplerin Geliş Hızı ile Geciken Parça Sayısı:}

EDD, S/OP kuralları kullanılarak tasarlanan algoritmada dikkat çeken nokta; gelişler arası süre arttığı zaman, geç kalan talep sayılarında azalış olduğudur, ki bu beklenen bir durumdur. Geliş peryodunun, kaynak kullanım değerlerini etkilemeyecek kadar azalması ile hiç şüphesiz bu performans ölçütünün her üç algoritma için de farkı 
olmayacaktır. Tasarlanan algoritma ile geç kalan parça sayısında yaklaşık \%78 iyileşme sağlanmıştır.

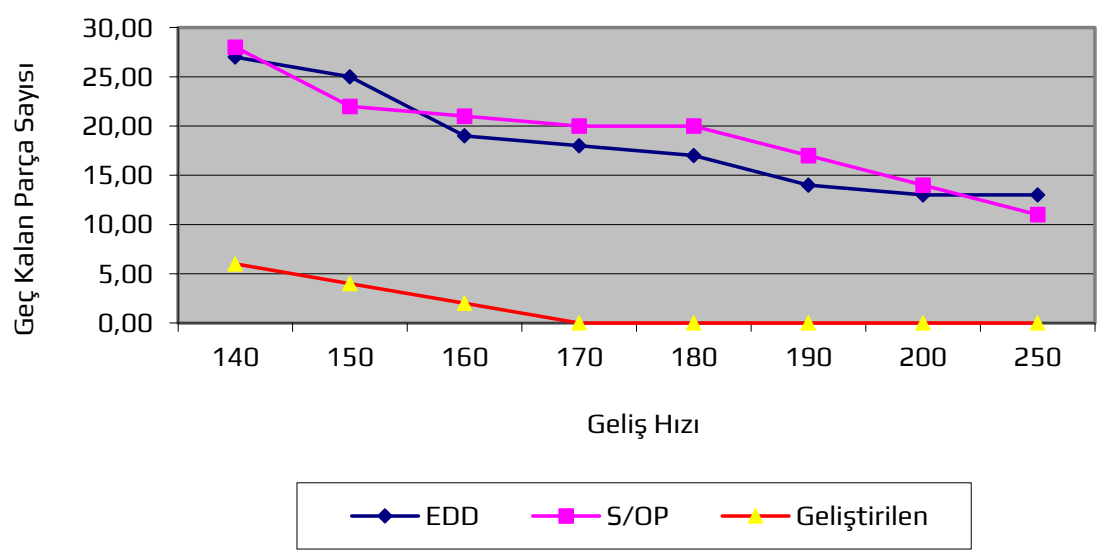

Şekil 6. Geliş Hızı-Geciken Parça Sayısı

\section{Talep Geliş Hızı-Erken Biten Parça Sayısı:}

Modellenen simülasyonun aktivasyon süresince, modellenen her algoritmada sisteme giren talep sayısı değişmemektedir. Böyle olması, karşılaştırma gerçekleştirmek adına da bir gerekliliktir. EDD ve S/OP kurallarında erken tamamlanan parça adetleri arasında büyük farklar bulunmamaktadır.

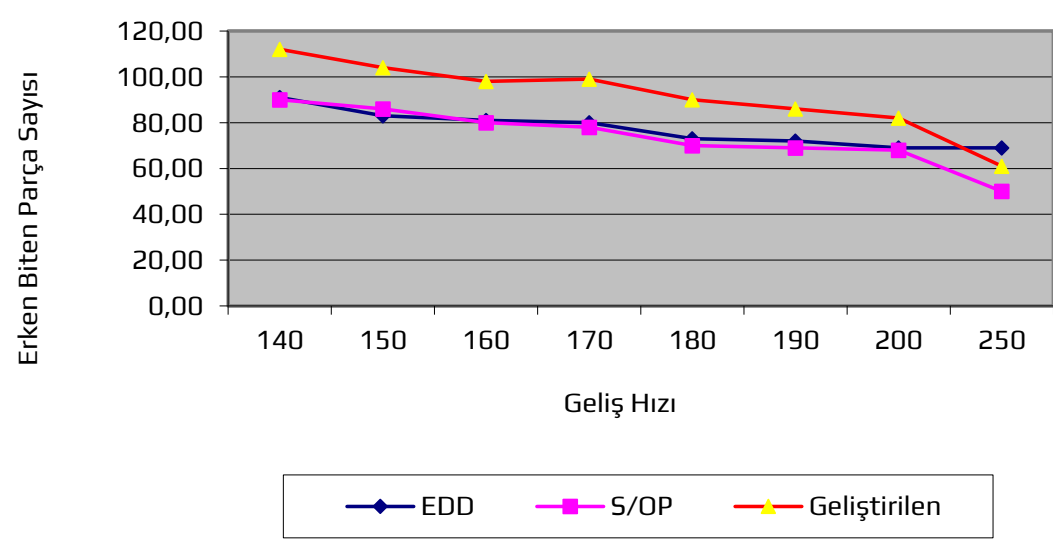

Şekil 7. Geliş Hızı-Erken Biten Parça Sayısı

\section{Talep Geliş̧ Hızı-Toplam Geç Kalma Süresi:}

Taleplerin toplamdaki gecikme (geç kalma) süreleri karşılaştırıldığında, EDD kuralı ile en kötü sonuca ulaşıırken; S/OP kuralı ile daha iyi sonuçlara varılmıştır. Tasarlanan algoritma neticesinde EDD kuralına kıyasla ortalama \%65, 5/OP kuralına göre de ortalama \%40 iyileşme olduğu görülmüştür. 


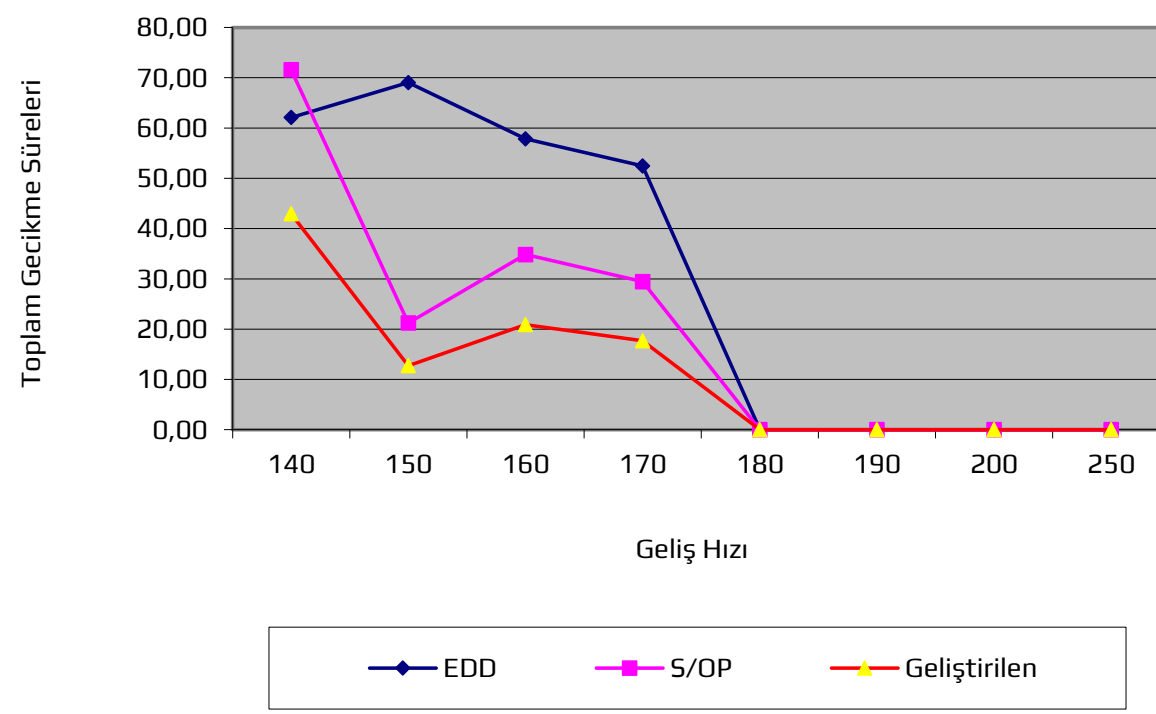

Şekil 8. Geliş Hızı-Toplam Gecikme Süreleri

\section{Talep Geliș Hızı-Toplam Erken Bitme Süresi:}

EDD ve S/OP kurallarında neticelerin yakın olmasıyla birlikte tasarlanan algoritmada yaklaşık \%28 artış sağlanmıştır.

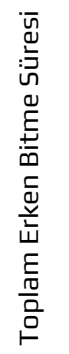

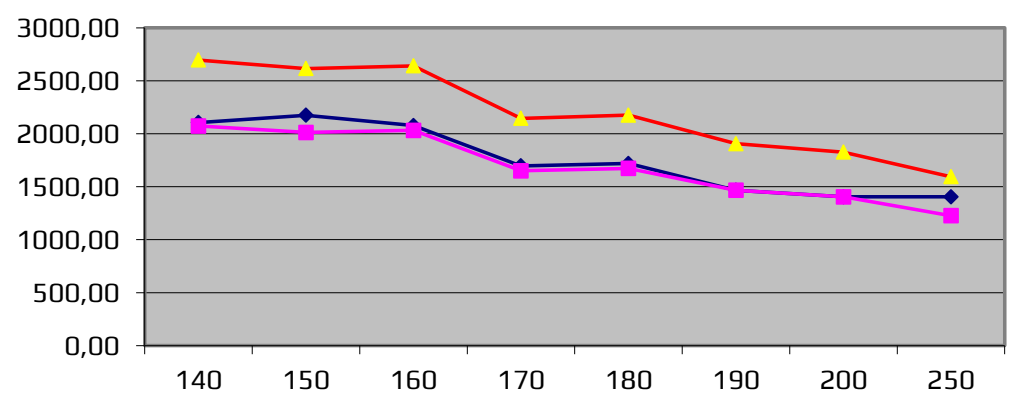

Geliş Hızı

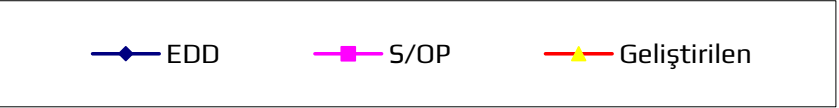

Şekil 9. Geliş Hızı-Toplam Erken Bitme Süresi

\section{Termin Süresi-Ortalama Akış Süresi:}

Termin süresinin ortalama akış süreleri üzerinde etkisi yoktur. Termin süresinin uzaması ya da kısalması, işlem süresini etkilememekte sadece önceliklerin değişmesine neden olmaktadır. Bunun ise sistem performansına etkisi çok azdır. 


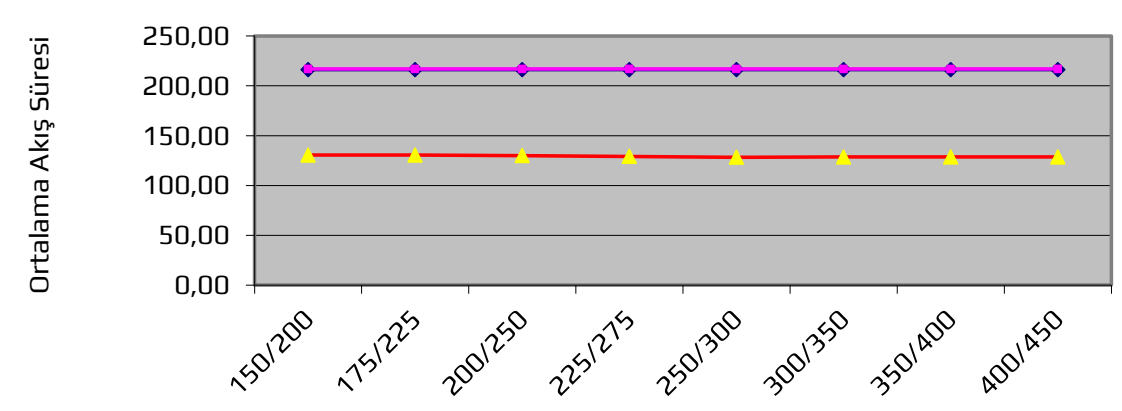

Teslim Süresi

$\longrightarrow$ EDD $\longrightarrow$ S/OP $\quad$ - Geliştirilen

Şekil 10. Termin Süresi-Ortalama Akış Süresi

\section{Termin Süresi-Geç Kalan Parça Sayısı:}

Beklenildiği gibi termin süresi arttıkça geç kalan parça sayısı azalmaktadır. EDD ve S/OP değerleri birbirine yakın hareket etmekte, tasarlanan algoritma ise diğerlerine oranla yaklaşık \%50 bir iyileşme sağlamıştır.

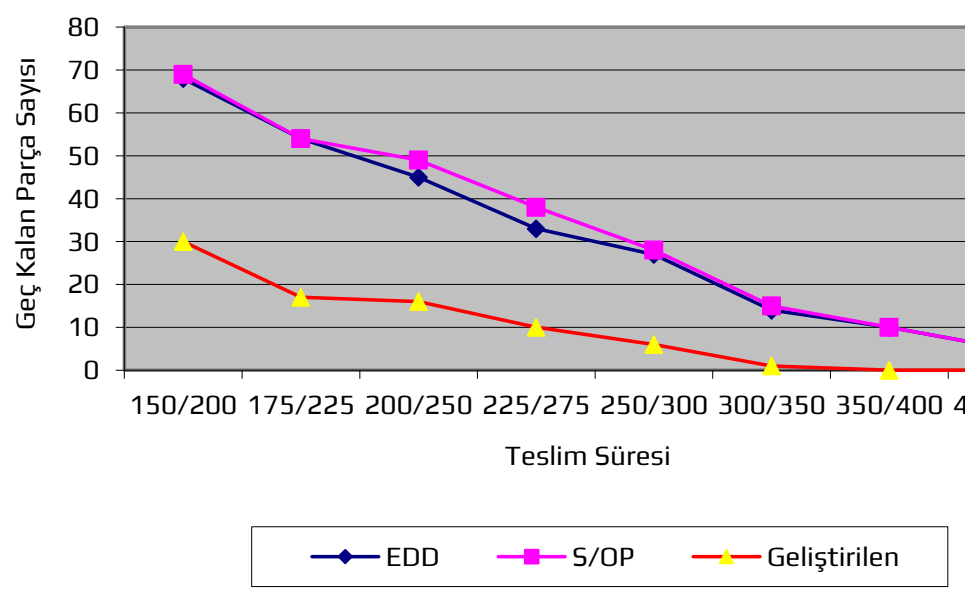

Şekil 11. Termin Süresi-Geç Kalan Parça Sayısı

\section{Sonuçlar ve Öneriler}

Günümüz montaj teknolojisinde ise, ortaya çıkan yeni ihtiyaçlar doğrultusunda aynı hatta birden fazla mamulü aynı anda üretmeye yönelik karışık montaj hatları gibi yeni yaklaşımlar da akademik çalışmaların odağı haline gelmektedir. Fakat karışık modelli montaj hatlarından faydalanılması için üretilecek modeller benzerlik taşımalı ve fazla ek işlem gerektirmeden aynı hat üzerinde üretilebilmelidir. Dengeleme sırasında hatta girecek modellerin sıralanması büyük önem taşımaktadır. Bu çalışmada tek modelli bir hat olan hafif kamyon hattı analiz edilmiş, ilgili problemler belirlenmiştir. Hattın darboğaz oluşturan istasyonunun iyileştirilmesine başka bir deyişle günlük hafif kamyon üretimi sayısının arttırılmasına çalışılmıştır. 
Bu bilgiler ışığında tasarlanan algoritma, en erken termin tarihli sıralama ve en kısa işlem süresi kuralları ile karşılaştırılmıştır. Sistemin hali hazırdaki durumu için tasarlanan yaklaşım ile diğer kurallar için yapılan denemelerin ardından, belirlenen performans kriterlerinde gösterdikleri etkinlikler de ayrı ayrı karşılaştırılmıştır.

Sonuç olarak;

- Geciken malzeme adetleri açısından ortalama \%78,

- Planlanan zamandan erken tamamlanan parça adetlerinde ortalama \%20,

- Akış süresi ortalamasında \%40,

- Toplam geç kalma sürelerinde EDD kuralına göre \%65, 5/OP kuralına göre \%40 iyileşme sağlanmıştır.

Dinamik bir durum söz konusu olduğundan, mesela talep geliş hızındaki değişiklik ya da termin sürelerinin farklılı̆ından kaynaklı olarak tasarlanan algoritma ve EDD ile S/OP kuralları tekrar ele alınmıştır. Farklı koşullarda bu kuralların farklı neticelere ulaştıracağı görülmüştür. Makale içinde tasarlanan algoritmanın ise bu farklı durumlarda, en iyi sonuçları verdiği tespit edilmiştir. Tamamlanan çalışmada taleplerin bir tek partide üretimi dikkate alınmıştır. Eğer partilerin ayrılarak gruplanabileceği esasına göre tasarlanan algoritmalar olması durumunda, daha iyi sonuçların alınabileceği belirlenmiştir. Varsayım olarak; aynı işlemi yapan makinelerin, operasyon sürelerinin de aynı olduğu düşünülmüş olup, bahse konu bu varsayım gelecekteki çalışmalarda değiştirilebilir. Makine duruşları, proses tekrarı ve bunun gibi olasılıklar göz ardı edilmiştir. Çalışmaya farkı boyut kazandırmak amacıyla ileride bu konuların da analizi yapılabilir.

\section{Kaynakça}

Acar, N., 1983. Üretim Planlama Yönetim ve Uygulamaları. MPM Yayınları, Ankara, 230.

Acar, N., 1984. Kesikli Seri Üretim Sistemlerinde Planlama ve Kontrol Çalışması. MPM Yayınları, Ankara, 309.

Ağpak, K., ve Gökçen, H., 2002. Basit U Tipi Montaj Hattı Dengeleme Problemine Bulanık Programlama Yaklaşımı. Dokuz Eylül Üniversitesi Fen ve Mühendislik Dergisi, 4 (2):29-40.

Ağpak K., Gökçen H., Saray, N., ve Özel, S., 2002. Stokastik Görev Zamanlı Tek Modelli U tipi Montaj Hattı Dengeleme Problemleri İçin Bir Sezgisel. Gazi Üniversitesi Mühendislik ve Mimarlık Fakültesi Dergisi, 17(4):115-124.

Askın, R. G., and Zhou, M., 1997. A Parallel Station Heuristic For The Mixed-Model Production Line Balancing Problem. International Journal Of Production Research, 35(11):3095-3105.

Bowman, E.H., 1960. Assembly Line Balancing by Linear Programming. Operation research, 18:3-18.

Chakravarty, A. K., and Shtub, A., 1985. Balancing Mixed-Model Lines with In-process Inventories. Management Science, 31(9):1161-1174.

Chakravarty, A. K., and Shtub, A., 1986. Cost Minimization Procedure for Mixed-Model Production Lines with Normally Distributed Task Times. Europen Journal Of Operation Research, 23: 2536.

Gonçalves, J. F., and De Almeıda, J. R., 2002. A Hybrid Genetic Algorithm for Assemly Line Balancing. Journal of Heuristics, (8):629-642.

Gökçen, H., ve Erel, E., 1995. Karışık Modelli Montaj Hattı Dengeleme Problemi için Bir Sezgisel Yöntem. Verimlilik Dergisi, (2):131-140.

Helgeson, W.B., and Bırnıe, D.P., 1982. Improving Assembly Line Efficiency. Computers and Operation Research, (4):75-80. 
Hoffman, T. R., 1963. Assembly Line Balancing with a predence Matrix. Management Science, (9):410.

Karayalçın, İ., 1986. Endüstri Mühendisliği ve Üretim Yönetimi. Çağlayan Basımevi, İstanbul, 10.

Kobu, B., 1987. Üretim Planlama Yönetim ve Uygulamaları. I.T.Ü İşletme Fakültesi Yayınları, İstanbul, 181.

Macaskıll, J.L.C., 1972. Production Line Balances for Mixed-Model Lines. Management Science, 19(4): 423-434.

Mansoor, E. M., 1964. Assembly Line Balancing - An Improvement on the ranked Positional Weight Technique. Journal of Industrial Engineering, (3):73-77.

Sarıkaya, B. 2005. Otomotiv Yan Sanayinde Bir Üretim Çizelgeleme Probleminin İncelenmesi. Yüksek Lisans Tezi, Adana.

Thomopoulos, L., 1970. Assembly Line Balancing. International Journal of Production Research, (19): 277-290.

Toraman, A., ve Gözlü, S., 1984. Üretim Planlama ve Kontrol. İstanbul Teknik Üniversitesi Basımevi, 116. 